\title{
Priorities for big biodiversity data
}

Laurance et al. (Front Ecol Environ 2016 14: 347) provide an insightful overview of advances in environmental data collection and access to Earth Observation datasets. If outstanding challenges can be conquered (Secades et al. 2014, Turner et al. 2015), such satellite-based remote sensing (SRS) can contribute significantly to biodiversity monitoring. We agree with the need to use SRS to measure natural systems and human impacts, to move from data collection to action and to develop better algorithms to process large volumes of data, but we would add additional priorities.

It is essential that satellite-based remote sensing is complemented by in situ monitoring to gather data on aspects of biodiversity that are difficult or impossible to detect from space (e.g. species distributions and abundance, exploitation levels, abundance of invasive alien species, pollution levels). Observations of species and threats are most valuable when generated from systematic protocols. Examples include Important Bird and Biodiversity Area monitoring (e.g. Buchanan et al. 2013), the Spatial Monitoring and Reporting Tool (SMART; www.smartconservationsoftware.org; Figure 1), and the TEAM Wildlife Monitoring Solution (www.teamnetwork.org/solution). In addition, citizen science data continue to increase in volume and scope (e.g. approximately 10 million observations are added monthly to eBird; www.ebird.org). Technological innovations allow more automated in situ data collection and processing. For example, advances in camera trap technology and associated monitoring protocols (Fegraus et al. 2013, Beaudrot et al. 2016) and acoustic recording devices allow capture of species images and sounds in the field alongside direct observations to complement images of habitat extent from space. Additional tools such as drones, weather dataloggers and audio and image recognition software hold promise for the future. The focus of data 
collection should expand beyond large mammals, birds and trees to address taxonomic imbalances in datasets (e.g. Butchart et al. 2010, Stephenson et al. 2015). While SRS and in situ monitoring are complementary - indeed, the application of SRS to conservation problems is strongly dependent on good in situ data - the scientific communities behind them need to collaborate more closely to increase synergies and efficiencies.

\section{The development of capacity for data collection and use within}

biodiversity-rich countries is vital. National capacity building should be linked to existing monitoring plans, such as those associated with national biodiversity strategies, to ensure governments are supported in implementing multilateral environment agreements, such as the Convention on Biological Diversity and the Strategic Plan for Biodiversity 2011-2020 (www.cbd.int/sp). While the increasing volume of available data undoubtedly represents an opportunity, converting data into usable information is not straightforward (e.g. Knight et al. 2010) and many national decision makers do not receive the information they need in formats they can use, especially if internet access is inadequate. Capacity and tools are required to convert data into derived products (synthesized reports, maps, dashboards, etc.) for easier interpretation by decision makers; this will be enhanced if products are developed and verified through appropriate science-policy interfaces that allow dialogue between data collectors and data users (Stephenson et al. 2016).

\section{More harmonization of monitoring systems is required. There is a} proliferation of environmental monitoring systems, databases and tools, some of which are similar to each other or not well-coordinated (e.g. the multiple platforms for species and protected areas). While this diversity reflects a dynamic sector, it is potentially confusing to end-users and spreads resources thinly while most existing databases, such as the IUCN Red List of Threatened Species (www.iucnredlist.org), 
Protected Planet (www.protectedplanet.net) and the Living Planet Index (www.livingplanetindex.org), are underfunded (Juffe-Bignoli et al. 2016). We support innovation and the development of improved systems but encourage all actors to collaborate in harmonizing databases and platforms and in enhancing interoperability and version control between them. New platforms should be based on adequate user needs assessments, respect terms of use of data providers, focus on filling data gaps and support the maintenance of underlying databases. System harmonization will require increased dialogue between SRS and conservation communities (Skidmore et al. 2015).

Several initiatives are harmonizing systems and building capacity for data collection and use, including the Eye on Earth Alliance (www.eoesummit.org), the IUCN SSC Species Monitoring Specialist Group (www.speciesmonitoring.org) and the work of GEO BON and its partners on Essential Biodiversity Variables (Pereira et al. 2013, Kissling et al. 2015). Key Biodiversity Areas (KBAs;

www.keybiodiversityareas.org) offer an additional opportunity to focus efforts on a common unit of monitoring, particularly given the breadth of the new KBA Partnership.

We agree with Laurance et al. that SRS has huge potential for conservation and research but argue for more investment in complementary in situ data collection and analysis, combined with more capacity building and systems harmonization, to fill observation gaps. A more holistic approach, combining satellite-based remote sensing and in situ observations, will monitor more effectively the state of nature and our impact upon it and ultimately improve the quality of environmental decisionmaking and conservation action. 


\section{P.J. Stephenson'1, Thomas M. Brooks ${ }^{2}$, Stuart H. M. Butchart3,4, Eric}

Fegraus5, Gary N. Geller6,7, Robert Hoft ${ }^{8}$, Jonathan Hutton ${ }^{89}$, Naomi Kingston ${ }^{10}$, Barney Long11 and Louise McRae ${ }^{12}$

${ }^{1}$ IUCN SSC Species Monitoring Specialist Group, c/o IUCN, Gland, Switzerland ${ }_{2}^{2}$ IUCN, Gland, Switzerland

3BirdLife International, Cambridge, UK

4Department of Zoology, University of Cambridge, UK

5Conservation International, Arlington, USA

${ }^{6}$ Group on Earth Observations (GEO), Geneva, Switzerland

7NASA Jet Propulsion Laboratory, California Institute of Technology, Pasadena, USA.

${ }^{8}$ Secretariat of the Convention on Biological Diversity, Montreal, Canada

9Luc Hoffmann Institute, Gland, Switzerland

10UNEP World Conservation Monitoring Centre, Cambridge, UK

${ }^{11}$ Global Wildlife Conservation, Washington DC, USA

12Zoological Society of London, London, UK

Beaudrot L, Ahumada JA, O'Brien T, et al. 2016. Standardized assessment of biodiversity trends in tropical forest protected areas: The end is not in sight. PLoS Biol 14(1): e1002357.doi:10.1371/journal.pbio.1002357

Buchanan, GM, Fishpool, LDC, Evans, MI and Butchart, SHM 2013. Comparing fieldbased monitoring and remote-sensing, using deforestation from logging at Important Bird Areas as a case study. Biol. Conserv. 167: 334-338.

Butchart, SHM, Walpole, M, Collen, B, et al. 2010. Global biodiversity: indicators of recent declines. Science 328: 1164-1168. 
Fegraus, EH, Lin, K, Ahumada, JA, et al. 2011. Data acquisition and management software for camera trap data: A case study from the TEAM Network. Ecol Inform 6: 345-353.

Juffe-Bignoli, D, Brooks, TM, Butchart, SHM, et al. 2016. Assessing the cost of global biodiversity and conservation knowledge. PloS One 11(8): p.eo160640.

Kissling, WD, Hardisty, A, García, EA, et al. 2015. Towards global interoperability for supporting biodiversity research on essential biodiversity variables (EBVs).

Biodiversity 16: 99-107.

Knight AT, Bode M, Fuller RA, et al. 2010. More action not more data. Science 9: 141. Pereira, HM, Ferrier, S, Walters, M, et al. 2013. Essential biodiversity variables. Science 339(6117): 277-278.

Secades, C, O’Connor, B, Brown, C, and Walpole, M. 2014. Earth observation for biodiversity monitoring: A review of current approaches and future opportunities for tracking progress towards the Aichi biodiversity Targets. $C B D$ Technical Series No. 72. Montreal, Canada: Secretariat of the Convention on Biological Diversity.

Skidmore, AK, Pettorelli, N, Coops, NC, et al. 2015. Agree on biodiversity metrics to track from space. Nature 523: 403-406.

Stephenson, PJ, Bowles-Newark, N, Regan, E, et al. 2016. Unblocking the flow of biodiversity data for decision-making in Africa. Biol Conserv. DOI: 10.1016/j.biocon.2016.09.003.

Stephenson, PJ, Burgess, ND, Jungmann, L. et al. 2015. Overcoming the challenges to conservation monitoring: integrating data from in situ reporting and global data sets to measure impact and performance. Biodiversity 16: 68-85.

Tittensor, DP, Walpole, M, Hill, SL, et al. 2014. A mid-term analysis of progress toward international biodiversity targets. Science 346: 241-244. 
Turner, W, Rondinini, C, Pettorelli, N, et al. 2015. Free and open-access satellite data are key to biodiversity conservation. Biol Conserv 182: 173-176.

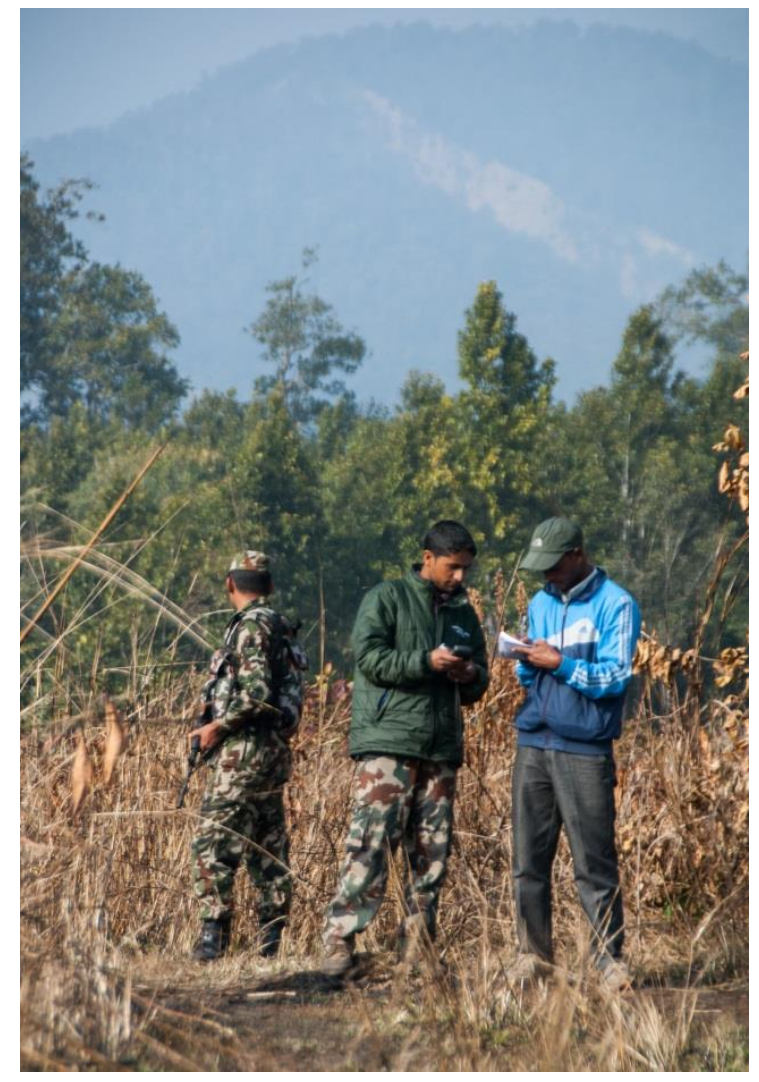

Figure 1. Field data being collected to feed into SMART (the Spatial Monitoring and Reporting Tool) in Nepal. Such methods for in-situ data collection complement satellite-based remote sensing and help provide a more complete picture of the status of species, their habitats and threats. Photograph @ Barney Long/WWF-US. 